\title{
Traqueobroncopatia osteocondroplástica em portador de tumor de Klatskin: relato de caso e revisão da literatura
}

\section{Tracheopathia osteochondroplastica in a patient with Klatskin tumor: a case report and review of the literature}

Fabíola Sawaguchi Faig-Leite'; Julio Defaveri²

\section{unitermos}

Traqueopatia

osteocondroplástica

Tumor de Klatskin

\section{resumo}

A traqueopatia osteocondroplástica (TO) é uma desordem idiopática, incomum, caracterizada pela presença de nódulos osteocartilaginosos na submucosa das vias aéreas, causando rigidez e estreitamento da árvore respiratória. Afeta principalmente homens acima dos 50 anos com manifestações clínicas devidas à obstrução e/ou a infecções locais. Sua patogênese é desconhecida. Relatamos um caso de TO encontrada acidentalmente em autopsia de mulher com 73 anos de idade, que apresentava carcinoma ductal biliar extra hepático (tumor de Klatskin). abstract

Tracheopathia osteochondroplastica (TO) is an unusual idiopathic disorder, characterized by osteocartilaginous nodules in the submucosa of the respiratory airway, which causes rigidity and narrowing of the respiratory tree. It affects mainly men over 50 and clinical manifestations are due to obstruction and/or local infections. The pathogenesis is uncertain. We report a case of TO found incidentally in an autopsy of a 73 year-old woman, who had an extrahepatic biliary ductal carcinoma (Klatskin tumor). key words

Tracheopathia

osteochondroplastica

Klatskin's tumor

1. Residente do primeiro ano de Clínica médica da Faculdade de Medicina de Botucatu da Universidade Estadual Paulista (UNESP). 


\section{Introdução}

A traqueopatia osteocondroplástica (TO) é uma anormalidade benigna rara, primeiramente descrita por Luschka (1856)(apud 1), Wilks (1857) (apud 2) e Virchow

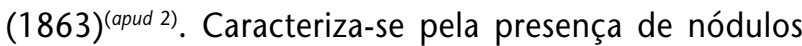
osteocartilaginosos, geralmente não-ulcerados, localizados principalmente na submucosa das paredes anterior $\mathrm{e}$ lateral da traquéia; menos comumente acomete laringe e segmentos iniciais dos brônquios-fonte. Apresenta-se como projeções osteocartilaginosas arredondadas ou polipóides tornando a superfície mucosa traqueobrônquica corrugada e a árvore respiratória rígida e estreita $(2,4,11)$

A etiologia e a patogênese da TO permanecem desconhecidas. Em geral a TO é descoberta acidentalmente durante broncoscopias ou em necropsias e não é associada a uma doença específica. Predomina no sexo masculino, entre a quinta e a sétima década de vida $^{(2,4,11)}$ e habitualmente é assintomática ${ }^{(5)}$.

A maioria das publicações sobre TO são relatos de caso $^{(5,7,8,10)}$, destacando-se os trabalhos de Ragaini et al. (apud 5) que relatam 20 casos em autópsias, Besso et al. (apud 5) e Härma et al..$^{(5)}$ ambos descrevendo 30 casos, e Leske et al. ${ }^{(7)}$, relatando 41 casos em biópsias.

No presente trabalho relatamos um caso de TO achado incidentalmente na necropsia de uma mulher com carcinoma de vias biliares extra-hepático (tumor de Klatskin $[\mathrm{TK}])^{(6)}$.

\section{Descrição do caso}

Paciente do sexo feminino, 73 anos, branca, portadora de TK diagnosticado quatro meses antes do óbito. À necropsia, confirmou-se o diagnóstico de TK com cirrose biliar secundária. Ao exame da árvore respiratória, observou-se traquéia bastante rígida e intensa irregularidade da superfície mucosa, com lesões sobrelevadas, globosas, irregulares de 0,5-2 cm de diâmetro, em geral bem demarcadas, de coloração branco-nacarada (Figuras 1 A e 1B) e consistência dura. Essas lesões comprometiam extensamente as superfícies ântero-laterais e discretamente a porção membranosa da traquéia; apresentavam-se 2-3 cm além dos ósteos dos brônquios-fonte lobares (Figura 1A). Em geral, a superfície mucosa estava intacta, esbranquiçada, porém havia fissuras longitudinais e áreas ulceradas (Figura 1B). Microscopicamente, os nódulos consistiam predominantemente de cartilagem, freqüentemente calcificadas e ossificadas, situadas entre a superfície mucosa e a cartilagem normal das vias aéreas, por vezes contendo medula óssea (Figura 2A). $O$ tecido osteocartilaginoso era envolto por fibrose densa (Figura 2B) e, em cortes seriados, observaram-se pontos de continuidade com as placas cartilaginosas traqueobrônquicas (Figura 2C). O epitélio que recobria os nódulos apresentava metaplasia pavimentosa em grande extensão e ulcerações (Figuras 2B e 2D). De permeio, havia infiltrado linfoplasmocitário.

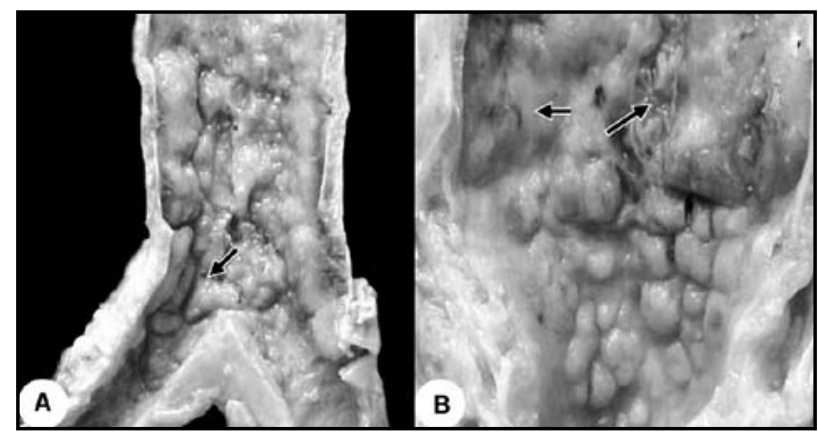

Figura 1 - A: Traquéia aberta longitudinalmente pela face membranosa. Paredes enrijecidas e superfície mucosa bastante irregular com projeções globosas, osteocartilaginosas para a luz, reduzindo-a intensamente, principalmente no ósteo do brônquio-fonte esquerdo (seta); B: maior aumento da mucosa mostrando as projeções osteocartilaginosas submucosas com áreas de ulcerações (setas). Superfície mucosa é esbranquiçada devido à metaplasia pavimentosa

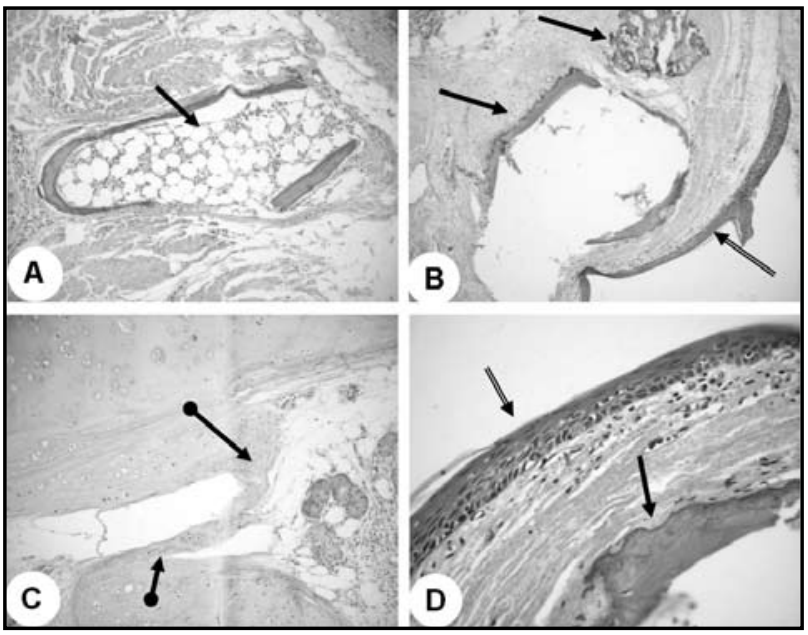

Figura 2 - A: Nódulo ósseo metaplásico com medula óssea (seta) (HE, 180x); B: nódulos ósseos metaplásicos submucosos (setas), o maior com o centro vazio por artefato. Há densa fibrose circunjacente aos nódulos e o epitélio que os recobre é metaplásico (dupla seta) (HE, 180x); C: conexão delicada entre o pericôndrio do anel cartilaginoso da traquéia (seta maior) e nódulo ósseo metaplásico (seta menor) (HE, 240x); D: maior aumento de B mostrando o epitélio metaplásico pavimentoso (seta dupla) recobrindo o nódulo ósseo metaplásico (seta simples) (HE, 340x) 


\section{Discussão e revisão da literatura}

A seleção dos artigos foi feita através da base de dados do PubMed até junho de 2007. Em 106 trabalhos revistos foram encontrados ao redor de 325 casos de TO.

A TO é uma doença rara e de curso benigno. Caracteriza-se pela formação de nódulos esbranquiçados ou amarelo-esbranquiçados de tecido cartilaginoso, ósseo e osteocartilaginoso na submucosa da laringe, da traquéia e, menos freqüentemente, dos brônquios principais. No presente caso, observou-se comprometimento dos três segmentos citados. Destacam-se no caso atual as ulcerações longitudinais e o comprometimento em parte da face posterior, membranosa, da traquéia, fato incomum quando em comparação com os diversos trabalhos analisados. $\mathrm{O}$ acometimento de pelo menos parte da porção membranosa da traquéia é responsável pela grande rigidez observada nesta. Microscopicamente as alterações encontradas foram as comumente descritas na TO, ou seja, metaplasia pavimentosa extensa do epitélio, nódulos osteocartilaginosos submucosos com calcificação e, por vezes, com presença de medula óssea.

O único trabalho que refere a porcentagem de alterações histopatológicas é o de Leske et al. ${ }^{(7)}$, que relata em 40 biópsias de TO ossificação (58\%), metaplasia escamosa do epitélio respiratório (48\%), cartilagem (38\%), calcificação (20\%) e amiloidose (13\%). Devese considerar que as alterações descritas em biópsia broncoscópica são limitadas pela dificuldade inerente ao exame em se obter amostras representativas das lesões. Contrariamente, a lesão é mais bem amostrada em material de necropsia, permitindo, por exemplo, constatar após cortes seriados, continuidade dos nódulos osteocartilaginosos com as placas cartilaginosas traqueobrônquicas e, também, a presença de medula óssea como observadas no presente caso.

Clinicamente a TO é assintomática em 50\% dos casos, sendo descoberta incidental durante intubação orotraqueal ${ }^{(8,10)}$ ou em necropsias ${ }^{(5)}$. Seus sintomas são devidos à obstrução, com tosse produtiva, dispnéia, sibilância, hemoptise e infecções de repetição do trato respirató$\mathrm{rio}^{(7)}$. Os sintomas de TO mais freqüentes encontrados na literatura foram tosse crônica, hemoptise, dispnéia aguda ou crônica e bronquite crônica catarral.

Os métodos diagnósticos mais utilizados são broncoscopia, tomografia computadorizada (TC), radiografia, ressonância magnética e biópsia. $\mathrm{O}$ diagnóstico definitivo só é obtido com a biópsia da lesão.

Não há terapêutica específica para a TO, sendo seu tratamento principalmente sintomático ${ }^{(11)}$.

A patogênese da TO não é conhecida. Várias hipóteses foram aventadas para sua origem, como infecções crônicas, base congênita, irritação química, mecânica ou infecciosa, distúrbio metabólico, processo degenerativo, econdrose e exostose, ou metaplasia do tecido elástico ${ }^{(3,5,7,11)}$. Recentemente, Tajima et al. ${ }^{(9)}$ analisaram em detalhes a morfologia da TO em dois casos de autopsia e observaram que nem todos os nódulos osteocartilaginosos estavam conectados aos anéis cartilaginosos, reforçando as hipóteses de que a TO pode se originar tanto por um processo de econdrose/exostose, quanto de metaplasia do tecido conjuntivo da árvore respiratória. De fato, eles detectaram nas lesões, pela imuno-histoquímica, a proteína morfogênica óssea (BMP-2) e o fator transformador do crescimento (TGF- $\beta 1$ ). A BMP-2 é responsável pela neoformação óssea e pela reparação através da diferenciação de células mesenquimais em cartilagem, mineralização e substituição por osso e formação de medula óssea hematopoiética. Essa proteína não está presente normalmente na árvore traqueobrônquica, sugerindo que a sua produção anormal seja responsável pela formação dos nódulos. Em altas concentrações, a BMP-2 aumenta a expressão ácido ribonucleico mensageiro (mRNA) do TGF- $\beta 1$, estimulando a produção das proteínas da matriz extracelular para os condrócitos ${ }^{(3)}$. Desse modo, os autores concluem que a proteína BMP-2 e o TGF- $\beta 1$ atuariam sinergisticamente na formação dos nódulos osteocartilaginosos característicos da TO.

A TO não está associada a uma doença específica. $\mathrm{Na}$ literatura, as doenças mais relacionadas foram a silicose, o carcinoma broncogênico, o linfoma não-Hodgkin, o cisto hepático e o carcinoma de mama. Não encontramos relato da associação da TO ao TK. Assim, julgamos que essa associação seja casual, reforçando a hipótese de que a TO é uma anomalia isolada traqueobrônquica. 


\section{Referências}

1. BOWEN, D. A. L. Tracheopathia osteoplastica. J Clin Path, v. 12, p. 435-8, 1959.

2. CORRIN, B.; NICHOLSON, A. G. Diseases of the airways. In: Pathology of the lungs. 2. ed. Londres: Elsevier, 1999. Cap 3, p. 87-130.

3. CUNNINGHAM, N. S.; PARALKAR, V.; REDDI, A. H. Osteogenin and recombinant bone morphogenetic protein $2 \mathrm{~B}$ are chemical for human monocytes and stimulate transforming growth factor $\beta 1$ mRNA expression. Proc Natl Acad Sci, v. 89, p. 11741-4, 1992.

4. DAIL, D. H. Metabolic and other diseases. In: DAIL, D. H.; HAMMAR, S. P. Pulmonary Pathology. 1. ed. Nova York: Springer-Verlag, 1988. Cap 20, p. 535-87.

5. HÄRMÄ, R. A.; SUUKARI, S. Tracheopathia condroosteoplastica: a clinical study of thirty cases. Acta Otolaryngol, v. 84, p. 118-23, 1977.

6. KLATSKIN, G. Adenocarcinoma of the hepatic duct at its bifurcation within the porta hepatis: an unusual tumor with distinctive clinical and pathological features. Am J Med, v. 38, p. 241-56, 1965.

7. LESKE, V. etal. Tracheobroncopathia osteochondropastica: a study of 41 patients. Medicine, v. 80, p. 378-90, 2001.

8. SUZUKI, H. et al. A case of tracheobronchopathia osteoplastica discovered incidentally by hypoxemia following the operation. Masui, v. 48, n. 3, p. 2835, 1999.

9. TAJIMA, K. et al. Immunohistochemical detection of bone morphogenetic protein-2 and transforming growth factor beta-1 in tracheopathia osteochondroplastica. Virchows Arch, v. 431, p. 359-63, 1997.

10. THOMAS, D.;STONELL, C.; HASAN, K. Tracheobronchopathia osteoplastica: incidental finding at tracheal intubation. Br J Anaesth, v. 87, n. 3, p. 515-7, 2001.

11. TRAVIS, W. D. et al. Miscellaneous diseases of uncertain etiology. In: Non-neoplastic disorders of the lower respiratory tract. 1. ed. Washington: AFIP\&ARP, 2002. Cap 17, p. 857-93. 